\title{
Factors associated with symptoms of reproductive tract infection/sexually transmitted infection and treatment seeking behavior among men in Tamil Nadu, India
}

\author{
Ramesh Chellan
}

State Facilitator-Demographer, UNICEF-PHDMA, Planning and Coordination Department, Government of Odisha, Bhubaneswar, Odisha, India.

\begin{abstract}
The International Conference on Population and Development (ICPD) Programme of Action paid attention to male sexual and reproductive health issues including RTI/STI as well as infertility, sexual dysfunction and sexual violence. In India, male reproductive health problems had been recognized as a public health issue. This paper is an attempt to examine the determinants of prevalence of RTI/STI and treatment seeking behavior and their socioeconomic and demographic characteristics in Tamil Nadu, India by using the data of the District Level Household Survey-Reproductive and Child Health Survey, 2002-04. The logistic regression and multinomial logistic regression models were used to determine factors associated with symptoms of RTI/STI and treatment seeking behavior for RTI/STI symptoms respectively. The study results indicated that about $2.8 \%$ of respondents reported at least one symptom of RTI/STI. One-fifth (19.5\%) of them had reported two or more symptoms. Among those who reported symptoms, $45.5 \%$ of men sought treatment from some sources. Multivariate analysis revealed that men residing in the Inland region, belonging to Muslim, men with high standard of living, and aware about HIV/AIDS were significantly less likely to report symptoms of RTI/STI. Men whose wife reported experience of symptoms of RTI/STI are significantly more likely to report symptom of RTI/STI. Further, men whose wife experienced symptoms of RTI/STI, and who ever discussed RTI/STI symptoms with their wife were significantly more likely to seek treatment from pubic as well as private health facility. The study suggests that there is an urgent need to address public health care services and a need to take necessary steps to provide quality health care and user friendly sexual and reproductive health care services.
\end{abstract}

Keywords: Sexual Health, RTI/STI, Treatment, Male, India.

\section{Introduction}

In recent years, much attention has been paid to sexual and reproductive health status of men especially after the International Conference on Population and Development (ICPD) held in Cairo in 1994. ${ }^{1}$ However, most of the developing countries have experienced high prevalence of sexual and reproductive health problems among general population. Sexual and reproductive health problems constitute a major public health problem in many developing countries. Many countries in Asia are experiencing noticeable increase in the prevalence of reproductive tract infection (RTI) and sexually transmitted infection (STI). For instance, India has more than two million people who are living with HIV/AIDS virus $^{2}$. The first HIV positive case in India was reported in 1986 from Chennai, Tamil Nadu. ${ }^{2-3}$ Therefore, the human immunodeficiency virus/acquired immune deficiency syndrome (HIV/AIDS) infection is a continuously growing serious threat in most of the developing countries including India. A study by Ndubani \& Hojer ${ }^{4}$ had shown $23 \%$ of young men were affected with sexually transmitted diseases (STD). In a developing country like India, men have a high risk of HIV/AIDS and other reproductive and sexual health problems.

Few studies have documented information about RTI/STI and treatment-seeking behavior across states in India.

\section{Practice Points}

- Men's sexual and reproductive health problems had been recognized as public health issues in India.

- This study showed less prevalence of RTI/STI among men in Tamil Nadu.

- Among those who reported symptoms, 45.5\% of men had sought treatment. Higher proportion of men had treatment from the private medical sector $(27.6 \%)$.

- Prevalence of RTI/STI was found to be significantly high among those who were aware of RTI/STI and men whose wife experience symptoms of RTI/STI. Men whose wife experienced symptoms of RTI/STI and discussed symptoms of RTI/STI with their wife had a positive effect on treatment seeking behavior for symptoms.

- There is an urgent need to focus on public health care services and also a need to take necessary steps to provide quality health care and user friendly sexual and reproductive health care services.

Correspondence: Dr. Ramesh Chellan, State Facilitator-Demographer, UNICEF-PHDMA, Planning and Coordination Department, Government of Odisha, Bhubaneswar, Odisha, India. Email: rameshchellan@gmail.com. 
According to Narayanan's study (1996) in Uttar Pradesh, $13 \%$ of men had experienced some symptoms of genital infection. ${ }^{5}$ Another study conducted in Uttar Pradesh on husband's reproductive health knowledge, attitudes and behavior among married men, reported $13 \%$ of men were experiencing at least one symptom of sexual health problems before marriage; more than onetenth of men stated that they had experienced at least one symptom after marriage and about $9 \%$ of men had reported any one symptom during the study. Out of the men who reported any one symptom, $62 \%$ of men had sought some sort of treatment before marriage, and $64 \%$ of men had sought treatment after marriage. ${ }^{6}$ A study in Odisha pointed out that more than half of men reported experience of discharge during night followed by itching $(40 \%)$ and semen discharge $(27 \%) .{ }^{7}$ Verma \& Stephen ${ }^{8}$ studied in Mumbai about male sexual health problems in which more than two-fifths of men reported at least one non-contact sexual health problem (wet dream, weakness, white discharge, early ejaculation, burning sensation, masturbation, quantity and quality of semen, and erection problems) and about $5 \%$ of men reported contact sexual health problems (boils, sores or ulcers in the genital area, pus discharge, and gonorrhea) during the last two months prior to the survey.

A study that was conducted on sexual behavior in rural India showed that $11 \%$ of men reported experience of genital discharge during the last 12 months, whereas 5\% of them reported experience of genital ulcers and sores among those who have reported genital ulcers and sores a large number of them did not seek any treatment. ${ }^{9}$ Verma \& Collumbien ${ }^{10}$ studied the sexual health problems among men in north-eastern part of Mumbai. Nearly one-third of those men reported experience of semen-related problem, sexual performance-related problems $(13 \%)$ and symptom of STI $(8 \%)$. Another study in Mumbai slums had reported that half of men were experienced with at least one sexual health problem. Among those who reported sexual health problems, a little more than one-fourth of them had taken some treatments. ${ }^{11} \mathrm{~A}$ number of socio-economic, demographic characteristics might be directly or indirectly associated with RTI/STI and treatmentseeking behavior. Few studies indicated high prevalence of RTI/STI and low tendency to seek care for RTI/STI among people in lower socio-economic status. ${ }^{10-13}$

In India, reproductive and sexual health care services for men were largely ignored by the public health programs in the initial phase. However, the Reproductive and Child Health ( $\mathrm{RCH}$ ) programme now includes reproductive health care services for men especially treatment for reproductive tract infection/ sexually transmitted infection. Efforts have therefore been made to assess the need for such services.

In this paper, we examined the prevalence of RTI/STI and treatment seeking behavior among currently married men in Tamil Nadu, India and analyzed the determinants of prevalence of RTI/STI and seeking health care and their socio-economic, and demographic characteristics in Tamil Nadu, India.

\section{Materials and Methods}

The data for this study was extracted from the District Level Household Survey-Reproductive and Child Health Survey (DLHS-RCH-2), 2002-04, conducted by International Institute for Population Sciences, Mumbai, India. ${ }^{14}$ Data was collected from a probability sample of 23,751 currently married men residing in 32,685 households which covered 30 districts of Tamil Nadu, India and the sample represented about $99 \%$ of Tamil Nadu's population. The survey broadly collected information on maternal and child heath, family planning, utilization of public health services and reproductive health problems. However, we focused on the symptoms of RTI/STI and treatment seeking behavior for symptoms in Tamil Nadu for the present study.

The second round of DLHS-RCH survey measured the prevalence of RTI/STI on the basis of self-reported symptoms occurring within three months prior to the survey and RTI/STI symptoms such as any discharge from penis, any sore/rash/redness on genital or anal area, difficulty/pain while urinating or very frequent urination, swelling of testes or in groin area (penis), and itching/irritation around genital. Further, the survey also took the treatment-seeking behavior and source of treatment for symptoms of RTI/STI into account.

This paper is based on self-reported RTI/STI symptoms rather than those clinically diagnosed. The self-reported symptom depends upon perceptions regarding symptoms. The prevalence of reproductive health problems are either directly or indirectly influenced by lack of knowledge about reproductive and sexual health, unprotected sex, low self-perceived vulnerability, and lack of access to health care services. Pervious literature suggested that prevalence of RTI/STI symptoms which might possibly be associated with a number of socio-economic factors such as place of residence, education, and household standard of living. In addition, the decision to seek care for reproductive health problems might also get influenced by many factors including perception of personal health risk, educational attainment, and socio-economic status. Twelve explanatory variables were considered for analysis. All explanatory variables were categorical. The explanatory variables were: region (coastalnorthern, coastal, southern, inland); religion (Hindu, Muslim, others); caste (OBC, SC/ST, others); education (non-literate, 0-5 years of schooling, 6-10 years of schooling, 11 and above years of schooling); standard of living (low, medium, high); age of men (15-24, 25-29, 30-34, 35-39, 40-44, 45+); condom use (non-user, user); aware of RTI/STI (not aware, aware); aware of HIV/ AIDS (not aware, aware); wife experienced any symptom of RTI/STI (no, yes); ever discussed RTI/STI symptom with wife (no, yes); and health facility in the village/residence (no health facility, with health facility, urban area). These variables were considered for analysis because they were likely to be associated with prevalence of RTI/STI and health seeking behavior.

First, the descriptive analyses were performed. Then binary logistic regression analysis was used in order to 
estimate the pure effect of each predictor variable on the probability of reporting symptoms of RTI/STI. Since our response variable on experience or reporting any symptom of RTI/STI was dichotomous (experience any symptoms of RTI/STI or not) the binary logistic regression model had been carried out as an alternative of multiple linear regression. ${ }^{15}$ For predictor variables in a categorized form, a category was designated as 'reference' and if Bk would be the binary logistic regression for category $\mathrm{k}$, then $\exp (\mathrm{Bk})$ the odds ratio, that is, the ratio of odds for the category $\mathrm{k}$ to the odds for the reference category. Further, since the variable on health seeking had three categories (no treatment, public health facility, private health facility); the multinomial logistic regression model was adopted to examine persuade of the various factors on this. In this model, two sets of coefficients (and odds ratios) were estimated: for the probability of seeking treatment from public health facility vis-à-vis no treatment, and for the probability of seeking treatment from private health facility vis-à-vis no treatment.

\section{Results and Discussion}

\section{Symptoms of RTI/STI}

The prevalence of various symptoms of RTI/STI among currently married men in Tamil Nadu is presented in Table 1 . The prevalence (actually period prevalence for a period of three months) was low as reported earlier. Only $2.8 \%$ of men in Tamil Nadu reported that they were experiencing some symptoms of RTI/STI during the reference period of three months prior to the survey. Among all symptoms, difficulty/pain while urinating or frequent urination $(1.1 \%)$, itching/irritation around genital $(1.2 \%)$ were the most commonly reported ones by the respondents. In addition, less than one $\%$ of men reported any sore/rash/redness on genital or anal area, any discharge from penis and swelling of testes or in groin area (penis). The severity of symptoms of RTI/ STI is indicated in Table 2, which gives the distribution of symptomatic men by number of symptoms. About $4 \%$ reported three or more symptoms of RTI/STI and nearly one-fifth (19\%) reported two or more symptoms of RTI/STI.

\section{Source of Treatment for RTI/STI Symptoms}

Not all the men with RTI/STI would seek treatment for it; while some might not felt that the symptoms were serious enough to warrant treatment and some others perhaps too shy to do so and for some they might not aware or could not access to treatment. Therefore, it is important to see the extent of treatment seeking. Besides we had also seen whether public health facilities were utilized or men obtained treatment from the private health facility. The DLHS survey data allowed doing an examination of these aspects. About half (45.5\%) of men who had reported any symptom of RTI/STI sought treatment (Table 3 ); private health facility $(27.6 \%)$ was accessed more than public health facility $(16.0 \%)$, and other facility $(3.0 \%)$. Men had sought treatment generally from non-governmental organization/trust hospital/clinic (12.9\%), chemist/medical shop (8.4\%) among private medical facility and from government/ municipal hospital $(7.6 \%)$, community health centre/ rural hospital $(5.5 \%)$ among public health facility for symptom of RTI/STI. Table 3 shows that the majority of men who reported any one symptom of RTI/STI had sought treatment from doctors $(33.1 \%)$ followed by chemist/medical shop (9.1\%) and home remedy (2.4\%).

Table 1: Prevalence of various symptoms of RTI/STI among men

\begin{tabular}{|l|c|}
\hline Types of RTI/STI symptom & Respondents (\%) \\
\hline Any discharge from penis & $87(0.4 \%)$ \\
\hline Any sore/rash/redness on genital or anal area & $134(0.4 \%)$ \\
\hline Difficulty/pain while urinating or very frequent urination & $218(1.1 \%)$ \\
\hline Swelling of testes or in groin area (penis) & $69(0.3 \%)$ \\
\hline Itching/irritation around genital & $266(1.2 \%)$ \\
\hline Any one symptom of RTI/STI & $607(2.8 \%)$ \\
\hline Number of men interviewed & $\mathbf{2 3 , 7 5 1}$ \\
\hline
\end{tabular}

Source: Computed from DLHS-RCH, 2002-04 data file.

Note: Based on self-reported symptoms during three months prior to the survey. The percentages are computed after applying survey sample weights and the number of men given is unweighted. The percentages for different symptoms do not add up to the percentage for any symptoms due to multiple responses.

Table 2: Married men who reported symptom of RTI/STI

\begin{tabular}{|l|c|}
\hline Number of symptoms reported & Respondents (\%) \\
\hline One symptom & $483(80.5 \%)$ \\
\hline Two symptoms & $99(15.9 \%)$ \\
\hline Three symptoms & $14(2.2 \%)$ \\
\hline Four symptoms & $4(0.5 \%)$ \\
\hline Five symptoms & $7(0.9 \%)$ \\
\hline At least one symptom & $607(100.0 \%)$ \\
\hline Average number of symptoms ${ }^{*}$ & 1.3 \\
\hline Number of men interviewed & $\mathbf{2 3 , 7 5 1}$ \\
\hline
\end{tabular}

Source: Computed from DLHS-RCH, 2002-04 data file. *Among those men who reported any symptom of RTI/STI.

Note: Based on self-reported symptoms during three months prior to the survey. The percentages are computed after applying survey sample weights and the number of men given was unweighted.

South East Asia Journal of Public Health 2014;4(2):7-15 
Table 3: Source of treatment for RTI/STI among men

\begin{tabular}{|c|c|c|}
\hline \multirow{2}{*}{ Source of treatment } & \multicolumn{2}{|c|}{ Respondents (\%) } \\
\hline & Reported symptom & Sought treatment \\
\hline Public Health Facility & $103(16.0 \%)$ & $103(35 \%)$ \\
\hline Government/municipal hospital & $49(7.6 \%)$ & $49(16.7 \%)$ \\
\hline Government dispensary & $4(0.5 \%)$ & $4(1.1 \%)$ \\
\hline UHC/UHP/UFWC & $4(0.6 \%)$ & $4(1.3 \%)$ \\
\hline CHC/rural hospital & $32(5.5 \%)$ & $32(12.2 \%)$ \\
\hline Primary health centre & $3(0.3 \%)$ & $3(0.7 \%)$ \\
\hline Health sub-centre & $13(2.0 \%)$ & $13(4.3 \%)$ \\
\hline Government ISM hospital/clinic & $4(0.4 \%)$ & $4(0.8 \%)$ \\
\hline Private Health Facility & $174(27.6 \%)$ & $174(60.6 \%)$ \\
\hline NGO/trust hospital/clinic & $85(12.9 \%)$ & $85(28.3 \%)$ \\
\hline Private hospital/clinic & $14(2.5 \%)$ & $14(5.4 \%)$ \\
\hline Private ISM hospital/clinic & $29(4.5 \%)$ & $29(9.8 \%)$ \\
\hline Chemist/medical shop & $50(8.4 \%)$ & $50(18.5 \%)$ \\
\hline Others & $18(3.0 \%)$ & $18(6.6 \%)$ \\
\hline \multicolumn{3}{|l|}{ Person Providing Treatment } \\
\hline Doctor & $209(33.1 \%)$ & $209(72.7 \%)$ \\
\hline Male health worker & $3(0.3 \%)$ & $3(0.7 \%)$ \\
\hline Traditional healer & $4(0.4 \%)$ & $4(0.8 \%)$ \\
\hline Relatives/friends & $5(0.6 \%)$ & $5(1.4 \%)$ \\
\hline ISM practitioner & $3(0.3 \%)$ & $3(0.6 \%)$ \\
\hline Home remedy & $15(2.4 \%)$ & $15(5.4 \%)$ \\
\hline Chemist/medical shop & $55(9.1 \%)$ & $55(20.1 \%)$ \\
\hline Other & $4(0.7 \%)$ & $4(1.5 \%)$ \\
\hline Sought treatment & $286(45.5 \%)$ & $286(100.0 \%)$ \\
\hline Did not seek any treatment & $320(54.2 \%)$ & NA \\
\hline Missing & $1(0.3 \%)$ & NA \\
\hline Number of men interviewed & 607 & 286 \\
\hline
\end{tabular}

Source: Computed from DLHS-RCH, 2002-04 data file. UHC $=$ Urban Health Centre; UHP $=$ Urban Health Post; UFWC $=$ Urban Family Welfare Centre; $\mathbf{C H C}=$ Community Health Centre; ISM= Indian System of Medicine; NGO= Nongovernmental Organization; NA= Not Applicable.

Note: The percentages are computed after applying survey sample weights and the number of men given is unweighted. Total number and percentages might add to more than 100.0 because of multiple responses.

Overall in Tamil Nadu, the prevalence of reproductive tract infection/sexually transmitted infection among men was low $(2.8 \%)$. Variations across regions of Tamil Nadu in the prevalence rate were low in absolute terms but notable in relative terms; the prevalence of symptoms of RTI/STI was ranging from $3.7 \%$ in the Southern region and $1.7 \%$ in the Inland region. The prevalence of RTI/STI varied across the socio-economic background of men. Table 4 clearly demonstrates that the prevalence rates were highest among the men residing in rural areas, belonging to the Hindu religion, belonging to Scheduled Castes (SC)/Scheduled Tribes (ST), those with low level of education, with low household standard of living, and young men (15-24 years). The prevalence could conceivably vary by awareness of sexual health matters (since it is based on self-reports) and also by condom usage and availability of health facility in the community (as this could lead to greater awareness and better reporting). In order to see this, special tabulations were made (Table 4). The prevalence of RTI/STI was relatively low among condom users. There is considerable evidence that the prevalence of RTI/STI would be relatively high among men who were not aware of HIV/AIDS (5.1\%) and men whose wife reported experience of RTI/STI (7.3\%).

Among those who reported some symptoms, more than twofifths sought treatment from any source. As noted earlier, 103 took treatment from the public health facility, 174 from private health facility, and 18 from other facility. Some took treatment from both public and private health facilities, but the number was very small, eight. For the purpose of further analysis, they were included only in the category of private health facility. Similarly, those who did not specify the type of facility (others) were also included in the private category. As the number of such persons were very small, this re-classification made very little difference but it simplified the analysis, with only three categories: public health facility, private health facility, and no treatment. There are considerable differences in treatment seeking behavior for their symptoms according to socio-economic background. In treatment seeking from the public health facility large differentials were observed by region, education, household standard of living, age of men, and awareness of HIV/AIDS (Table 5). Illiterate men and those in the age group of 40-44 years have had a high tendency to seek treatment from the public health facility for RTI/STI. Besides, men residing in the southern region, those belonging to the other backward castes, men $\geq 11$ years of schooling, high household standard of living, in the age of 45 and above years, users of condom, and aware of HIV/AIDS were more likely to seek treatment from the private health facility. 


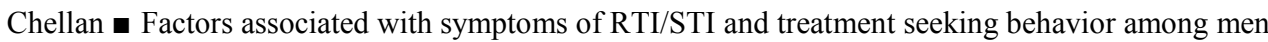

Table 4: Socio-economic characteristics of married men who reported any symptom of RTI/STI

\begin{tabular}{|c|c|c|}
\hline Background characteristics & Men interviewed & $\begin{array}{c}\text { Men who reported any symptom } \\
\text { of RTI/STI (\%) }\end{array}$ \\
\hline \multicolumn{3}{|r|}{ (n) } \\
\hline Coastal-northern & 5,641 & $168(2.7 \%)$ \\
\hline Coastal & 6,076 & $218(4.0 \%)$ \\
\hline Southern & 7,257 & $150(3.1 \%)$ \\
\hline Inland & 4,777 & $71(1.7 \%)$ \\
\hline \multicolumn{3}{|l|}{ Residence } \\
\hline Rural & 13,338 & $444(3.6 \%)$ \\
\hline Urban & 10,413 & $163(1.7 \%)$ \\
\hline \multicolumn{3}{|l|}{ Religion } \\
\hline Hindu & 21,132 & $566(2.9 \%)$ \\
\hline Muslim & 1,272 & $16(1.2 \%)$ \\
\hline Others (Christian) & 1,347 & $25(2.1 \%)$ \\
\hline \multicolumn{3}{|l|}{ Caste } \\
\hline $\mathrm{OBC}$ & 16,902 & $391(2.5 \%)$ \\
\hline $\mathrm{SC} / \mathrm{ST}$ & 6,431 & $214(3.6 \%)$ \\
\hline Others & 417 & $2(0.2 \%)$ \\
\hline \multicolumn{3}{|l|}{ Education } \\
\hline Non-literate & 4,340 & $150(3.6 \%)$ \\
\hline $0-5$ years of schooling ${ }^{\dagger}$ & 4,321 & $150(3.8 \%)$ \\
\hline $6-10$ years of schooling & 9,777 & $232(2.6 \%)$ \\
\hline 11 and above years of schooling & 5,313 & $75(1.5 \%)$ \\
\hline \multicolumn{3}{|l|}{ Standard of living } \\
\hline Low & 6,888 & $232(3.7 \%)$ \\
\hline Medium & 9,812 & $276(3.1 \%)$ \\
\hline High & 7,051 & $99(1.4 \%)$ \\
\hline \multicolumn{3}{|l|}{ Age of men (Years) } \\
\hline $15-24$ & 809 & $39(4.9 \%)$ \\
\hline $25-29$ & 3,317 & $96(3.4 \%)$ \\
\hline $30-34$ & 4,807 & $107(2.6 \%)$ \\
\hline $35-39$ & 5,053 & $128(2.7 \%)$ \\
\hline $40-44$ & 4,059 & $106(2.6 \%)$ \\
\hline $45+$ & 5,706 & $131(2.3 \%)$ \\
\hline \multicolumn{3}{|l|}{ Condom use } \\
\hline Non-user & 23,252 & $600(2.8 \%)$ \\
\hline User & 499 & $7(1.4 \%)$ \\
\hline \multicolumn{3}{|l|}{ Aware of RTI/STI } \\
\hline Not aware & 5,719 & $146(2.9 \%)$ \\
\hline Aware & 18,030 & $461(2.7 \%)$ \\
\hline \multicolumn{3}{|l|}{ Aware of HIV/AIDS } \\
\hline Not aware & 484 & $27(5.1 \%)$ \\
\hline Aware & 23,267 & $580(2.7 \%)$ \\
\hline \multicolumn{3}{|c|}{ Wife experienced any symptom of RTI/STI } \\
\hline No & 19,630 & $328(1.8 \%)$ \\
\hline Yes & 4,121 & $279(7.3 \%)$ \\
\hline \multicolumn{3}{|l|}{ Health facility in the village } \\
\hline No health facility & 6,118 & $190(3.4 \%)$ \\
\hline With health facility & 7,220 & $254(3.7 \%)$ \\
\hline Urban area & 10,413 & $163(1.7 \%)$ \\
\hline All Men & 23,751 & $607(2.8 \%)$ \\
\hline
\end{tabular}

Source: Computed from DLHS-RCH, 2002-04 data file. $\uparrow=$ Literate men with no years of schooling are included.

Note: Based on self-reported symptoms during three months prior to the survey. The percentages are computed after applying survey sample weights and the number of men given is unweighted. Total number of men may not add to $n$ due to missing cases.

Factors affecting symptoms of RTI/STI

In the analysis of prevalence of symptom of RTI/STI, the binary logistic regression model had been used because the dependent variable was dichotomous: reported symptom and not reported symptom. Table 6 presents regression coefficients, standard errors along with odds ratios for selected variables from the logistic regression analysis of prevalence of RTI/STI. The influences of various variables as seen in this analysis are 'net' of the influences of other variables included in the regression. Men belonging to the coastal region were significantly 
Table 5: Treatment seeking behavior of men with symptoms of RTI/STI

\begin{tabular}{|c|c|c|c|c|}
\hline \multirow{2}{*}{ Background characteristics } & \multirow{2}{*}{$\begin{array}{l}\text { Men who } \\
\text { reported any } \\
\text { symptom }\end{array}$} & \multicolumn{3}{|c|}{ Respondents (\%) } \\
\hline & & No treatment & Public healthcare & Private healthcare \\
\hline \multicolumn{5}{|l|}{ Region } \\
\hline Coastal-northern & 168 & $95(55.7 \%)$ & $23(15.7 \%)$ & $50(28.6 \%)$ \\
\hline Coastal & 218 & $113(51.6 \%)$ & $41(18.2 \%)$ & $64(30.2 \%)$ \\
\hline Southern & 150 & $67(45.4 \%)$ & $21(13.7 \%)$ & $62(41.0 \%)$ \\
\hline Inland & 71 & $47(73.8 \%)$ & $10(10.7 \%)$ & $14(15.5 \%)$ \\
\hline \multicolumn{5}{|l|}{ Residence } \\
\hline Rural & 444 & $232(53.4 \%)$ & $73(15.4 \%)$ & $139(31.2 \%)$ \\
\hline Urban & 163 & $90(58.0 \%)$ & $22(13.8 \%)$ & $51(28.2 \%)$ \\
\hline \multicolumn{5}{|l|}{ Religion } \\
\hline Hindu & 566 & $301(54.9 \%)$ & $89(15.2 \%)$ & $176(29.8 \%)$ \\
\hline Non-Hindu & 41 & $21(50.0 \%)$ & $6(12.5 \%)$ & $14(37.5 \%)$ \\
\hline \multicolumn{5}{|l|}{ Caste } \\
\hline $\mathrm{SC} / \mathrm{ST}$ & 214 & $112(57.3 \%)$ & $38(18.8 \%)$ & $54(23.9 \%)$ \\
\hline Non-SC/ST & 393 & $200(53.2 \%)$ & $57(13.0 \%)$ & $136(33.8 \%)$ \\
\hline \multicolumn{5}{|l|}{ Education } \\
\hline Non-literate & 150 & $90(58.6 \%)$ & $28(21.0 \%)$ & $32(20.4 \%)$ \\
\hline $0-5$ years of schooling ${ }^{\dagger}$ & 150 & $85(60.7 \%)$ & $22(13.5 \%)$ & $43(25.8 \%)$ \\
\hline $6-10$ years of schooling & 232 & $110(49.2 \%)$ & $40(15.2 \%)$ & $82(35.5 \%)$ \\
\hline 11 and above years of schooling & 75 & $37(52.0 \%)$ & $5(4.0 \%)$ & $33(44.0 \%)$ \\
\hline \multicolumn{5}{|l|}{ Standard of living } \\
\hline Low & 232 & $130(58.8 \%)$ & $39(16.0 \%)$ & $63(25.1 \%)$ \\
\hline Medium & 276 & $149(54.8 \%)$ & $48(16.3 \%)$ & $79(28.8 \%)$ \\
\hline High & 99 & $43(44.6 \%)$ & $8(7.9 \%)$ & $48(47.5 \%)$ \\
\hline \multicolumn{5}{|l|}{ Age of men (Years) } \\
\hline $15-24$ & 39 & $25(60.5 \%)$ & $3(11.6 \%)$ & $11(27.9 \%)$ \\
\hline $25-29$ & 96 & $57(60.0 \%)$ & $12(13.9 \%)$ & $27(26.1 \%)$ \\
\hline $30-34$ & 107 & $66(63.0 \%)$ & $12(8.7 \%)$ & $29(28.3 \%)$ \\
\hline $35-39$ & 128 & $64(54.3 \%)$ & $21(13.8 \%)$ & $43(31.9 \%)$ \\
\hline $40-44$ & 106 & $50(46.7 \%)$ & $24(23.8 \%)$ & $32(29.5 \%)$ \\
\hline $45+$ & 131 & $60(46.5 \%)$ & $23(17.8 \%)$ & $48(35.7 \%)$ \\
\hline \multicolumn{5}{|l|}{ Condom use } \\
\hline Not-user & 600 & $319(54.8 \%)$ & $95(15.2 \%)$ & $186(30.0 \%)$ \\
\hline User & 7 & $3(42.9 \%)$ & $0(0.0 \%)$ & $4(57.1 \%)$ \\
\hline \multicolumn{5}{|l|}{ Aware of RTI/STI } \\
\hline Not aware & 146 & $85(60.5 \%)$ & $22(15.0 \%)$ & $39(24.6 \%)$ \\
\hline Aware & 461 & $237(52.8 \%)$ & $73(15.1 \%)$ & $151(32.1 \%)$ \\
\hline \multicolumn{5}{|l|}{ Aware of HIV/AIDS } \\
\hline Not aware & 27 & $22(83.3 \%)$ & $1(3.3 \%)$ & $4(13.3 \%)$ \\
\hline Aware & 580 & $300(53.3 \%)$ & $94(15.6 \%)$ & $186(31.1 \%)$ \\
\hline \multicolumn{5}{|c|}{ Wife experienced any symptom of RTI/STI } \\
\hline No & 328 & $192(60.7 \%)$ & $47(12.5 \%)$ & $89(26.9 \%)$ \\
\hline Yes & 279 & $130(47.4 \%)$ & $48(18.1 \%)$ & $101(34.5 \%)$ \\
\hline \multicolumn{5}{|c|}{ Ever discussed RTI/STI problem with wife } \\
\hline No & 386 & $252(66.6 \%)$ & $42(10.0 \%)$ & $92(23.4 \%)$ \\
\hline Yes & 217 & $66(31.9 \%)$ & $53(24.6 \%)$ & $98(43.5 \%)$ \\
\hline \multicolumn{5}{|l|}{ Health facility in the village } \\
\hline No health facility & 190 & $107(57.8 \%)$ & $27(12.7 \%)$ & $56(29.4 \%)$ \\
\hline With health facility & 254 & $125(50.0 \%)$ & $46(17.6 \%)$ & $83(32.4 \%)$ \\
\hline Urban area & 163 & $90(58.0 \%)$ & $22(13.8 \%)$ & $51(28.2 \%)$ \\
\hline All Men & 607 & $322(54.7 \%)$ & $95(15.0 \%)$ & $190(30.3 \%)$ \\
\hline
\end{tabular}

Source: Computed from DLHS-RCH, 2002-04 data file. $\dagger=$ Literate men with no years of schooling are included.

more likely, but those from the Inland region less likely to have RTI/STI compared to men belonging to the southern region. The probability of prevalence of RTI/STI was found to be significantly low among Muslim men than among Hindu men. Men with six and above years of schooling and men who belong to high standard of living were found to be significantly less likely to be affected by RTI/STI than illiterate and those with low standard of living respectively. The prevalence of RTI/STI was significantly less likely in the age group of 45 and above years than men in the age groups of 25-29 years. The reported prevalence of RTI/STI was significantly higher among those who were aware of RTI/STI compared to men who were not aware. But this could be reciprocal effect as well, since prevalence of symptoms could influence awareness. On the other hand, the prevalence of RTI/STI was observed to be significantly low among men aware of HIV/AIDS than 
Table 6: Logistic regression analysis of the prevalence of RTI/STI by background characteristics among men

\begin{tabular}{|c|c|c|c|}
\hline \multirow[b]{2}{*}{ Background characteristics } & \multicolumn{3}{|c|}{ Prevalence of RTI/STI } \\
\hline & B & S.E. & Odds Ratio \\
\hline \multicolumn{4}{|l|}{ Region } \\
\hline \multicolumn{4}{|l|}{ Southern (RC) } \\
\hline Coastal-northern & -0.171 & 0.106 & 0.843 \\
\hline Coastal & 0.310 & 0.114 & $1.363 * *$ \\
\hline Inland & -0.509 & 0.127 & $0.601 * *$ \\
\hline \multicolumn{4}{|l|}{ Religion } \\
\hline \multicolumn{4}{|l|}{ Hindu (RC) } \\
\hline Muslim & -0.598 & 0.268 & $0.550^{*}$ \\
\hline Others (Christian) & -0.283 & 0.212 & 0.753 \\
\hline \multicolumn{4}{|l|}{ Caste } \\
\hline \multicolumn{4}{|l|}{ OBC (RC) } \\
\hline $\mathrm{SC} / \mathrm{ST}$ & 0.113 & 0.089 & 1.120 \\
\hline Others & -1.507 & 0.851 & 0.222 \\
\hline \multicolumn{4}{|l|}{ Education } \\
\hline \multicolumn{4}{|l|}{ Non-literate (RC) } \\
\hline $0-5$ years of schooling & 0.130 & 0.118 & 1.139 \\
\hline $6-10$ years of schooling & -0.234 & 0.113 & $0.791^{*}$ \\
\hline 11 and above years of schooling & -0.454 & 0.162 & $0.635^{* *}$ \\
\hline \multicolumn{4}{|l|}{ Standard of living } \\
\hline \multicolumn{4}{|l|}{ Low (RC) } \\
\hline Medium & 0.044 & 0.094 & 1.045 \\
\hline High & -0.306 & 0.147 & $0.737^{*}$ \\
\hline \multicolumn{4}{|l|}{ Age of men (Years) } \\
\hline \multicolumn{4}{|l|}{$25-29(\mathrm{RC})$} \\
\hline $15-24$ & 0.332 & 0.186 & 1.394 \\
\hline $30-34$ & -0.223 & 0.133 & 0.800 \\
\hline $35-39$ & -0.229 & 0.131 & 0.795 \\
\hline $40-44$ & -0.237 & 0.140 & 0.789 \\
\hline $45+$ & -0.451 & 0.134 & $0.637 * *$ \\
\hline \multicolumn{4}{|l|}{ Condom use } \\
\hline \multicolumn{4}{|l|}{ No (RC) } \\
\hline Yes & -0.251 & 0.391 & 0.778 \\
\hline \multicolumn{4}{|l|}{ Aware of RTI/STI } \\
\hline \multicolumn{4}{|l|}{ No (RC) } \\
\hline Yes & 0.235 & 0.099 & $1.265^{*}$ \\
\hline \multicolumn{4}{|l|}{ Aware of HIV/AIDS } \\
\hline \multicolumn{4}{|l|}{ No (RC) } \\
\hline Yes & -0.693 & 0.204 & $0.500 * *$ \\
\hline \multicolumn{4}{|l|}{ Wife experienced symptom of RTI/STI } \\
\hline \multicolumn{4}{|l|}{ No $(\mathrm{RC})$} \\
\hline Yes & 1.326 & 0.082 & $3.765 * *$ \\
\hline Health provider in the village & & & \\
\hline No health provider in the village $(\mathrm{P}$ & & & \\
\hline With health provider in the village & 0.179 & 0.096 & 1.196 \\
\hline Urban area & -0.200 & 0.114 & 0.819 \\
\hline Constant & -2.933 & 0.253 & $0.053 * *$ \\
\hline Number of women & & 23,748 & \\
\hline -2log likelihood & & $5,535.65$ & \\
\hline Pseudo R Square (Nagelkerke) & & 0.09 & \\
\hline
\end{tabular}

$\mathbf{R C}=$ Reference Category; * = Indicates significant level at $0.05 ; * *=$ Indicates significant level at 0.01 .

men not aware of HIV/AIDS. Men whose wife reported experience of symptom of RTI/STI were significantly more likely to report symptom of RTI/STI compared to men whose wife did not report symptom of RTI/STI when other variables were controlled.

\section{Treatment seeking behavior for RTI/STI}

In the analysis of health seeking behavior for RTI/STI, the present study had used multinomial logistic regression model because the response variable was having more than two categories: no treatment, treatment from public health facility, and treatment from private health facility. It is important to see both whether men seek treatment for RTI/STI but also whether they do so from the public sector or the private sector. In addition, those who took treatment from both public and private health facilities and those who did not specify the sector were deemed to have taken treatment from the private health facility for the purpose of analysis; such cases were very few. Besides, religion, use of condom, and awareness of HIV/AIDS variables were excluded from the multivariate analysis because many categories of these have had less than 50 unweighted cases. Table 7 presents summary results of two sets of coefficients, standard errors and odds ratios, for treatment from the public health facility vis-à-vis no 
Table 7: Multinomial logistic regression analysis of treatment-seeking behavior by background characteristics among men

\begin{tabular}{|c|c|c|c|c|c|c|}
\hline \multirow[t]{2}{*}{ Background characteristics } & \multicolumn{3}{|c|}{$\begin{array}{c}\text { Public health facilities/ } \\
\text { No treatment }\end{array}$} & \multicolumn{3}{|c|}{$\begin{array}{c}\text { Private health facilities/ } \\
\text { No treatment }\end{array}$} \\
\hline & B & S.E. & Odds Ratio & B & S.E. & Odds Ratio \\
\hline \multicolumn{7}{|l|}{ Region } \\
\hline \multicolumn{7}{|l|}{ Southern (RC) } \\
\hline Coastal-northern & -0.104 & 0.331 & 0.902 & -0.361 & 0.251 & 0.697 \\
\hline Coastal & 0.329 & 0.350 & 1.390 & -0.396 & 0.273 & 0.673 \\
\hline Inland & -0.753 & 0.424 & 0.471 & -1.484 & 0.349 & $0.227 * *$ \\
\hline \multicolumn{7}{|l|}{ Caste } \\
\hline \multicolumn{7}{|l|}{ Non-SC/ST (RC) } \\
\hline $\mathrm{SC} / \mathrm{ST}$ & 0.328 & 0.270 & 1.388 & -0.242 & 0.226 & 0.785 \\
\hline \multicolumn{7}{|l|}{ Education } \\
\hline \multicolumn{7}{|l|}{ Non-literate (RC) } \\
\hline $0-5$ years of schooling & -0.443 & 0.339 & 0.642 & 0.041 & 0.303 & 1.042 \\
\hline $6-10$ years of schooling & -0.018 & 0.316 & 0.982 & 0.590 & 0.281 & $1.804^{*}$ \\
\hline 11 and above years of schooling & -1.015 & 0.647 & 0.362 & 0.855 & 0.370 & $2.351^{*}$ \\
\hline \multicolumn{7}{|l|}{ Standard of living } \\
\hline \multicolumn{7}{|l|}{ Low (RC) } \\
\hline Medium & 0.258 & 0.273 & 1.295 & 0.207 & 0.227 & 1.230 \\
\hline High & -0.037 & 0.497 & 0.964 & 0.751 & 0.339 & $2.120 *$ \\
\hline \multicolumn{7}{|l|}{ Age of men (Years) } \\
\hline \multicolumn{7}{|l|}{$15-29(\mathrm{RC})$} \\
\hline $30-34$ & -0.621 & 0.436 & 0.537 & -0.209 & 0.315 & 0.811 \\
\hline $35-39$ & -0.001 & 0.379 & 0.999 & 0.103 & 0.300 & 1.109 \\
\hline $40-44$ & 0.519 & 0.387 & 1.680 & 0.091 & 0.337 & 1.096 \\
\hline $45+$ & 0.338 & 0.383 & 1.403 & 0.388 & 0.311 & 1.475 \\
\hline \multicolumn{7}{|l|}{ Aware of RTI/STI } \\
\hline \multicolumn{7}{|l|}{ No (RC) } \\
\hline Yes & 0.161 & 0.294 & 1.174 & 0.140 & 0.239 & 1.151 \\
\hline \multicolumn{7}{|l|}{ Wife experienced symptom of RTI/STI } \\
\hline \multicolumn{7}{|l|}{ No (RC) } \\
\hline Yes & 0.556 & 0.257 & $1.743^{*}$ & 0.546 & 0.206 & $1.727 * *$ \\
\hline \multicolumn{7}{|c|}{ Ever discussed RTI/STI symptom with wife } \\
\hline \multicolumn{7}{|c|}{ No (RC) } \\
\hline Yes & 1.673 & 0.256 & $5.327 * *$ & 1.427 & 0.210 & $4.165 * *$ \\
\hline \multicolumn{7}{|l|}{ Health facility in the village/Residence } \\
\hline \multicolumn{7}{|l|}{ Rural area: No health facility (RC) } \\
\hline Rural area: With health facility & 0.360 & 0.300 & 1.433 & 0.090 & 0.235 & 1.095 \\
\hline Urban area & 0.394 & 0.356 & 1.483 & -0.210 & 0.280 & 0.811 \\
\hline Intercept & -2.627 & 0.534 & & -1.575 & 0.427 & \\
\hline Number of cases & \multicolumn{6}{|c|}{607} \\
\hline -2log likelihood & \multicolumn{6}{|c|}{$1,056.95$} \\
\hline Pseudo R Square (Nagelkerke) & \multicolumn{6}{|c|}{0.27} \\
\hline
\end{tabular}

$\mathbf{R C}=$ Reference Category. ${ }^{*}$ Indicates significant level at $0.05 . * *$ Indicates significant level at 0.01 .

treatment, and treatment from the private health facility vis-à-vis no treatment. Men living in the Inland region were significantly less likely to seek care for RTI/STI from the private health facility compared to men living in the southern region. Caste did not show any significant effect on treatment seeking behavior when other variables were controlled. Men with high school or higher education were significantly more likely to seek care from the private health facility than illiterate men. As expected, men with high standard of living were significantly more likely to seek care for RTI/STI from the private health facility compared to men with low standard of living. Men who ever discussed RTI/ STI symptom with their wife were statistically significantly more likely to seek care for symptom of RTI/STI from the public health as well as private health facilities compared to other men. Again, there could be reciprocal effect, taking treatment leading to discussion with wife.

\section{Conclusion}

This study showed very low prevalence of RTI/STI among currently married men in Tamil Nadu, $2.8 \%$, as reported by the respondents themselves during 20022004. It is possible that many men did not report symptoms due to shyness and the actual prevalence may be higher, but this is a limitation of a large survey especially about sexual health. More than two-fifth of the respondent had taken treatment from some source among those who had reported symptoms of RTI/STI. The higher proportion of men had treatment from the private medical sector $(27.6 \%)$ than the public medical sector $(16.0 \%)$. This could be due to poor access to public health care facilities for reproductive health problems. Additional private health care services may be easily access in the community. However, the prevalence of RTI/STI and health seeking behavior varies across the socio-economic conditions of the respondent. The multivariate logistic regression analysis 
clearly explained that men belonging to the coastal region, men belonging to the $\mathrm{SC} / \mathrm{ST}$, in the age group of 15-24 years, aware of RTI/STI, and whose wife experienced symptom of RTI/STI were significantly more likely to report symptom of RTI/STI compared to the corresponding reference category. In addition, among those who experienced symptoms of RTI/STI, men aware of HIV/AIDS, men whose wife experienced symptoms and who ever discussed about RTI/STI symptom with their wife were more intended to seek treatment from the public health facility. Similarly, young men (15-24 years) were significantly less likely to seek treatment than men in the age group of 25-29 years. On the other hand, men who belong to the Inland region, men with 6-10 and 11 and above years of schooling, high standard of living, aware of HIV/AIDS, whose wife experienced symptom of RTI/STI, and who ever discussed RTI/STI symptom with their wife were more likely to seek treatment for symptoms from private health facility compared to reference category.

The symptoms of RTI/STI are a very sensitive and public health concern. The lack of awareness of sexual and reproductive health problems may lead to high prevalence rate. In addition, the lack of health care services from the public health sector can also lead men towards the end when it may be fatal. Therefore, public health care services need to take necessary steps to provide quality health care and user friendly reproductive health care services. There are some evidence highlighting the reproductive health problems among male population. But they have not drawn enough attention from a public health perspective. Therefore, public health related programs and policymakers should focus more on male reproductive health issues and introduce reproductive and sexual health education, information and services to improve reproductive health and also promote family reproductive health status. It is thus necessary to improve the health infrastructure and make them more people oriented. This may help the younger generation to overcome the lack of awareness of reproductive and sexual health and further, to reduce the threat of chronic and fatal diseases like HIV/AIDS in the country.

\section{Acknowledgement}

The author is indebted to the International Institute for Population Sciences, Mumbai, for providing him with the raw data from DLHS-2. The earlier version of the paper was presented at the First Asian Population Association Conference on November 16-20, 2010 at the Vigyan Bhawan, New Delhi, India. The author is solely responsible for the interpretations or any error in the analysis.

\section{Conflict of interest}

The author has declared that there is no competing interest.

\section{References}

1. United Nations. Programme of Action Adopted at the International Conference on Population and Development, Cairo, 5-13 September 1994. New York: United Nations, 1994.

2. John T, Jacob P, Babu G, Jaykumari H, Simoes EAF. Prevalence of HIV infection in risk groups in Tamil Nadu, India. Lancet 1987;1:160-1.

3. UNAIDS. Global Report: UNAIDS Report on the Global AIDS Epidemic 2013, Geneva: UNAIDS, 2013.

4. Ndubani P, Hojer B. Sexual behaviour and sexually transmitted diseases among young men in Zambia. Health Policy Plann 2001;16(1):10712.

5. Narayana G. Family violence, sex and reproductive heath behaviour among men in Uttar Pradesh, India, 1996 (Unpublished)

6. Singh KK, Bloom SS, Tsui AO. Husband's reproductive health knowledge, attitudes, and behaviour in Uttar Pradesh, India. Stud Family Plann 1998;29(4): 388-99.

7. Collumbien M, Bohidar N, Das R, Das B, Pelto P. Male sexual health concerns in Orissa: An emic perspective. IUSSP working paper for the seminar on Social Categories in Population Health, Cairo, Egypt, 15-18 September 1999.

8. Verma RK, Schensul SL. Male Sexual health problems in Mumbai: Cultural constructs that present opportunities for HIV/AIDS risk education. In: Verma RK, Pelto PJ, Schensul SL, Joshi A (Eds). Sexuality in the Time of AIDS: Contemporary Perspectives from Communities in India. New Delhi: Sage Publications, 2004.

9. UNFPA. Rural Sexual Behaviour in India. New Delhi: UNFPA, 2003.

10. Verma RK, Collumbien M. Wife Beating and the Link with Poor Sexual Health and Risk Behaviour among Men in Urban Slums in India. J Comp Family Stud 2003;34(1):61-75.

11. Verma, RK, Sharma S, Singh R, Rangaiyan G, Pelto PJ. Beliefs Concerning Sexual Health Problems and Treatment Seeking among Men in an Indian Slum Community. Cult Health Sex 2003;5(3):265-76

12. Desai GS, Patel RM. Incidence of Reproductive Tract Infections and sexually transmitted diseases in India: Levels and Differentials. J Fam Welfare 2011;57(2):48-60.

13. Das NP, Shah U. A Study of reproductive health problems among men and women in urban slums with special reference to sexually transmitted infections. A Project Report prepared for ICMR, New Delhi. Population Research Centre, M.S. University of Baroda, Baroda, 2007.

14. International Institute for Population Sciences (IIPS). District Level Household Survey Reproductive and Child Health, 2002-04, India. Mumbai: IIPS, 2006. 